\title{
Changes in Human In vivo Serotonin and Dopamine Transporter Availabilities during Chronic Antidepressant Administration
}

\author{
Akira Kugaya*,', Nicholas M Seneca', Peter J Snyder², Stephen A Williams², Robert T Malison', \\ Ronald M Baldwin', John P Seibyl ${ }^{3}$ and Robert B Innis ${ }^{1,4}$ \\ 'Department of Psychiatry, Yale University School of Medicine, New Haven, CT, USA; ${ }^{2}$ Pfizer Global Research \& Development, Groton, CT, USA; \\ ${ }^{3}$ The Institute for Neurodegenerative Disorders, New Haven, CT, USA; ${ }^{4}$ Department of Pharmacology, Yale University School of Medicine, New \\ Haven, CT, USA
}

\begin{abstract}
Few studies have demonstrated in vivo alterations of human serotonin and dopamine transporters (SERTS and DATS) during antidepressant treatment. The current study measured these transporter availabilities with $\left[{ }^{123} \mid\right] \beta$-CIT single photon emission computed tomography (SPECT) during administration of selective serotonin reuptake inhibitors (SSRIs) or a non-SSRI, bupropion. A total of 17 healthy human subjects were randomly assigned to two different treatment protocols: ( I) citalopram ( $40 \mathrm{mg} /$ day) followed by augmentation with bupropion (100 mg/day) or (2) bupropion (100-200 mg/day) for 16 days. Citalopram significantly inhibited [ ${ }^{123}$ I] $\beta$ CIT binding to SERT in brainstem (51.4\%) and diencephalon (39.4\%) after 8 days of administration, which was similarly observed after 16 days. In contrast, citalopram significantly increased striatal DAT binding by 15-17\% after 8 and 16 days of administration. Bupropion and its augmentation to citalopram did not have a significant effect on DAT or SERT. In 10 depressed patients who were treated with paroxetine $(20 \mathrm{mg} / \mathrm{day})$, a similar increase in DAT and inhibition of SERT were observed during 6 weeks treatment. The results demonstrated the inhibition of SERT by SSRI in human in vivo during the chronic treatment and, unexpectedly, an elevation of DAT. This apparent SSRI-induced modulation of the dopamine system may be associated with the side effects of these agents, including sexual dysfunction.
\end{abstract}

Neuropsychopharmacology (2003) 28, 413-420. doi:10.1038/sj.npp. 1300036

Keywords: serotonin and dopamine transporters; single photon emission computed tomography; antidepressants

\section{INTRODUCTION}

Selective serotonin reuptake inhibitors (SSRIs) are effective treatments for several psychiatric disorders, including major depression, panic disorder, obsessive-compulsive disorder and post-traumatic stress disorder (Schatzberg, 2000). The serotonin transporter (SERT) is present in high densities in raphe nuclei, midline thalmic nuclei, substantia nigra and hypothalamus as shown with radiolabeled paroxetine binding in human postmortem brain (Cortes et $a l, 1988)$ and with radiolabeled citalopram binding in rat brain (D'Amato et al, 1987). SSRIs inhibition of SERT is considered an initial and essential component of their mechanism of action (Hyttel, 1982; Benfield et al, 1986;

\footnotetext{
*Correspondence: Dr A Kugaya, I16A2, 950 Campbell Avenue, VA Connecticut Healthcare System, West Haven, CT 065I, USA, Tel: +I 203932 57II, Fax: + I 2039373897 , E-mail: akira.kugaya@yale.edu

Received 28 February 2002; revised 9 May 2002; accepted 16 July 2002 Online publication: 19 July 2002 at http://www.acnp.org/citations/ Npp7190235।
}

Wong et al, 1995). However, few studies in the living human brain have assessed changes in SERT (occupancy and potential adaptive changes) during acute and chronic SSRI treatment.

The present study was designed to measure radioligand binding to SERT and dopamine transporter (DAT) binding during antidepressant administration to healthy and depressed subjects. The brain uptake of $\left[{ }^{123} \mathrm{I}\right] \beta$-CIT $\left(\left[{ }^{123} \mathrm{I}\right]\right.$ methyl $3 \beta$-(4-iodophenyl) tropane-2 $\beta$-carboxylate) was measured with single photon emission computed tomography (SPECT) and used as a measure of SERT and DAT. Our previous study in monkeys showed that $\left[{ }^{123} \mathrm{I}\right] \beta$ CIT binding in diencephalon and brainstem was displaced by an SSRI, citalopram, but not by a selective DAT inhibitor (GBR 12909), whereas the reverse was true for binding of this ligand in striatum (Laruelle et al, 1993). These results indicated that diencephalon and brainstem $\left[{ }^{123} \mathrm{I}\right] \beta$-CIT binding reflects SERT, while striatal $\left[{ }^{123} \mathrm{I}\right] \beta$-CIT uptake reflects DAT. The differential localization of brain regions with highest levels of DAT (striatum) and SERT (brainstem and diencephalon) allows a single radiotracer with mixed 
affinity to provide a partial measure of these two transporters. However, the lack of selectivity of $\left[{ }^{123} \mathrm{I}\right] \beta$ CIT for these two monoamine transporters does not provide a pure measure of either one, although the measurement of SERT is more problematic than DAT. The relative density of DAT and SERT in primate striatum is approximately 12:1 (B Madras, personal communication) and $\left[{ }^{123} \mathrm{I}\right] \beta$-CIT has approximately three-fold higher affinity for DAT over SERT (Neumeyer et al, 1991). Based on these data, $\left[{ }^{123} \mathrm{I}\right] \beta$-CIT binding under tracer conditions in striatum would be predicted to reflect largely binding of DAT to SERT, with a ratio of approximately $36: 1$ - that is, about $3 \%$ of striatal uptake would reflect SERT. Similar calculations are difficult to perform for the midbrain uptake of $\left[{ }^{123} \mathrm{I}\right] \beta$-CIT, since one needs the average density of DAT and SERT in a large region, where much more specific localizations have been reported (Laruelle et al, 1988; Backstrom et al, 1989; De Keyser et al, 1989). Nevertheless, the high DAT density in the substantia nigra suggests that a sizeable proportion of midbrain $\left[{ }^{123} \mathrm{I}\right] \beta$-CIT uptake will reflect DAT as well as SERT. Pirker et al (1995) reported that treatment of depressed patients with $20 \mathrm{mg}$ citalopram caused $\sim 50 \%$ occupancy of midbrain uptake of $\left[{ }^{123} \mathrm{I}\right] \beta$-CIT, with higher doses of 40 and $80 \mathrm{mg}$ not causing greater displacement. These data suggest that SERT is fully occupied by citalopram at $20 \mathrm{mg}$ and that the baseline midbrain uptake of $\left[{ }^{123} \mathrm{I}\right] \beta$-CIT is approximately equally divided between DAT and SERT.

We selected two different antidepressants to investigate the effects on DAT and SERT binding in healthy subjects: citalopram and bupropion sustained release (SR). Citalopram is perhaps the most selective serotonin reuptake inhibitor, as shown by $\mathrm{IC}_{50}(\mathrm{nM})$ to inhibit uptake of radiolabeled monoamines into rat synaptosomes of 1.8 for serotonin, 41000 for dopamine, and 8800 for norepinephrine (Hyttel, 1982; Willetts et al, 1999). Bupropion has greater affinity for DAT, with $\mathrm{IC}_{50}(\mu \mathrm{M})$ values of 58 for serotonin, 2.0 for dopamine and 5.0 for noradrenaline (Ascher et al, 1995). We examined the effects of citalopram and bupropion, both separately and in combination, since the addition of bupropion to an SSRI has been reported to alleviate the sexual dysfunction caused by SSRIs (Ashton and Rosen, 1998; Clayton et al, 2001). We also report the effects of a potent SSRI, paroxetine, on DAT and SERT levels in depressed patients.

\section{METHODS}

\section{Subjects}

Healthy subjects were recruited by a local newspaper advertisement. A physical examination, laboratory workup, and EKG were performed to rule out any clinically significant abnormalities and medical conditions. Subjects were free of any lifetime psychiatric illness (Axis I) based on the Structured Clinical Interview for DSM-III-R (SCID). Non-Patient Edition (Spitzer et al, 1990a). Subjects were excluded for a history of taking antidepressants and for use of any psychotropic medication within 6 months, except one female who had taken loratidine 5 days prior (the elimination half-life of loratadine is $8.4 \mathrm{~h}$ ). All subjects reported no concomitant medication, except two females on birth control pill (norgestimate and ethynyl estradiol) and a male on nadolol during the course of the study. A total of 17 eligible subjects (10 males and seven females; 10 Caucasian, four African-American, one Hispanic, and two Asian; four left-handed) completed the study. One subject (a 45-yearold female Caucasian) withdrew because of a mild anxiety attack during the administration of bupropion. The two subjects who had taken loratidine or had been taking nadolol were both assigned to Group 1 in the following randomization.

Depressed patients were 10 of 15 subjects who participated in the baseline $\left[{ }^{123} \mathrm{I}\right] \beta$-CIT binding study reported previously by our group (Malison et al, 1998). Patients met DSM-III-R criteria for unipolar major depressive disorder and were diagnosed according to SCID Patient Edition (Spitzer et al, 1990b). Their mean age was $46.4 \pm 7.6$ (six males and four females; nine Caucasian and one Hispanic, with these and subsequent data expressed as mean \pm SD). Previously treated subjects $(N=6)$ were antidepressant-free for a minimum of 3 weeks before the study. None of the most recent antidepressants was fluoxetine. Three of them were the first episode of depression. The number of previous depressive episodes $(N=6)$ was $1.7 \pm 1.4$ (one patient had uncountable episodes in the past). Their baseline Hamilton Depression Rating Scale (HDRS; 19item) was $22.7 \pm 4.6$. All subjects (healthy and depressed) provided written informed consent for participation in this study, which was approved by the Yale Human Investigations Committee.

\section{Drug Administration}

Healthy subjects were randomly assigned to one of two different protocols: Group $1(N=8$; two males and six females; mean age $33.4 \pm 13.6$ ) received bupropion hydrochloride SR $100 \mathrm{mg} \mathrm{qAM}$ for 8 days and $200 \mathrm{mg}$ qAM for another 8 days. Group $2(N=9$; eight males and one female; mean age $37.4 \pm 14.3$ ) received citalopram $40 \mathrm{mg}$ b.i.d for 8 days and citalopram $40 \mathrm{mg}$ b.i.d and bupropion hydrochloride SR $100 \mathrm{mg}$ qAM for another 8 days. Plasma levels of bupropion and its metabolites (hydroxybupropion and erythro/threobupropion), which can be reuptake inhibitors (Sanchez and Hyttel, 1999), were measured on days 7 and 15 before injection of $\left[{ }^{123} \mathrm{I}\right] \beta$-CIT. Plasma levels of citalopram were not measured because the assay was not available.

Depressed patients were treated with paroxetine $20 \mathrm{mg}$ for 6 weeks. Plasma levels of paroxetine were not measured because the assay was not available.

\section{SPECT Imaging}

All 17 healthy subjects completed three SPECT scans: day 0 (baseline; before drug administration), day 8, and day 16. The second scan (day 8) examined the occupancy of the transporters by the medications at or near steady-state plasma levels. The plasma elimination half-lives of citalopram and bupropion SR are 35 and $24 \mathrm{~h}$, respectively. Based on these half-lives and to obtain steady-state plasma levels, the time points (days 8 and 16) were selected. The third scan (day 16) was also expected to measure potential changes in the transporter availability after the chronic administration. $\left[{ }^{123} \mathrm{I}\right] \beta$-CIT was injected $244 \pm 131$ and $278 \pm 91 \mathrm{~min}$ after 
the morning dose of drug on days 7 and 15 , respectively. On days 8 and 16, approximately $24 \mathrm{~h}$ after the administration of $\left[{ }^{123} \mathrm{I}\right] \beta$-CIT, subjects came back for a SPECT scan that began $264 \pm 95$ and $229 \pm 100 \mathrm{~min}$, respectively, after the morning dose of the drug.

Nine of 10 depressed subjects completed three SPECT scans: baseline (before drug administration), between 1 and 3 weeks after, and 6 weeks after beginning paroxetine treatment. The second scan examined the transporter occupancy by the medication, while the third scan was chosen to measure the transporter changes potentially linked to clinical efficacy. One subject withdrew himself after the second scan.

$\left[{ }^{123} \mathrm{I}\right] \beta$-CIT was synthesized as previously described (Baldwin et al, 1993). Healthy subjects were pretreated with 10 drops of Lugol's solution by mouth before injection of a mean of $222 \pm 22 \mathrm{MBq}$ of $\left.{ }^{123} \mathrm{I}\right] \beta$-CIT. SPECT scanning was performed at $24.3 \pm 1.9 \mathrm{~h}$ after injection, when $\left[{ }^{123} \mathrm{I}\right] \beta$-CIT binding is at equilibrium and SERT and DAT binding can be estimated by the ratios of specific to nondisplaceable uptake (Laruelle et al, 1994). For depressed subjects, a mean of $215 \pm 26 \mathrm{MBq}$ of $\left[{ }^{123} \mathrm{I}\right] \beta$-CIT was administered, and SPECT scanning was performed at $24.9 \pm 1.5 \mathrm{~h}$ after injection. The injected dose (ID) and the duration between the injection and the scan were not significantly different between baseline and treatment scan(s) and between Groups 1 and 2 (data not shown). SPECT scanning was performed with a triple-headed, Picker PRISM 3000 camera (Cleveland, $\mathrm{OH}$ ), equipped with a low-energy, high-resolution fan beam collimator. Resolution of this system, estimated with a line source in a scattering medium, is $12 \mathrm{~mm}$ full-width at half-maximum in all three axes. SPECT scanning began with the simultaneous acquisition of a 15min transmission scan with a line source containing $20 \mathrm{mCi}$ ${ }^{57} \mathrm{Co}$, followed by removal of the line source and acquisition of a 24-min emission scan (19 scans of depressed patients were acquired for $20 \mathrm{~min}$ ). Both emission and transmission scans were acquired in continuous mode with $128 \times 128$ matrix, $3.56 \mathrm{~mm}$ slice thickness, 120 angular range, 3 angular step, 40 steps, $36 \mathrm{~s} / \mathrm{step}$, and $15.5 \mathrm{~cm}$ radius of rotation.

The previous test/retest reliability study in healthy subjects demonstrated excellent reproducibility of the measurement of striatal binding with variability of $6.8 \pm$ $6.8 \%$ and intraclass correlation coefficient $\rho$ of 0.96 (Seibyl et al, 1996). An axial MRI scan was acquired (T1 weighted 3DSPGR sequence, NPW/GRX TR $=25 \mathrm{~ms}, \mathrm{TE}=5 \mathrm{~ms}, 30$ flip angle, $F O V=24,256 \times 256$ matrix, slice thickness $3 \mathrm{~mm}$ ) on all subjects for coregistration with SPECT emission images.

\section{Image Reconstruction and Analysis}

SPECT emission scans were reconstructed from photo peak counts $(20 \%$ energy window centered on $159 \mathrm{keV})$ with a Butterworth filter (power factor $=10$, cutoff $=0.24$ cycles $/ \mathrm{s}$ ). Transmission scans were reconstructed with a Bayesian algorithm and a smoothing Gibbs prior. Nonuniform attenuation correction of the emission images was then performed using software developed on site (Rajeevan et al, 1998). Three SPECT transmission scans were independently coregistered to the MRI scan by using a surface-matching algorithm in MEDx (Sensor Systems, Sterling, VA) (Pelizzari et al, 1989), and the same three-dimensional transformation was applied to each attenuation-corrected emission scan. By using this minor modification to the original procedure (Jacobsen et al, 2000; Staley et al, 2001), three emission scans were resliced the same number of times and transformed into the same orientation.

Region of interest analysis for healthy subjects followed the method described by Staley et al (2001). Both the MRI and the coregistered emission scans were reoriented so that the axial plane was parallel to the intercommissural plane. Standardized regions of interest (the right and left striatum, eight slices each; diencephalon, four slices; brainstem, eight slices; right and left cerebellum, six slices each) were placed on the MRI, and three-dimensional volumes of interest (striatum, $9.5 \mathrm{~cm}^{3}$ for each side; diencephalon, $1.9 \mathrm{~cm}^{3}$; brainstem, $3.7 \mathrm{~cm}^{3}$; cerebellum, $43.2 \mathrm{~cm}^{3}$ for each side) were created. The brainstem volume of interest included the superior and inferior colliculi and nuclei of the midbrain (substantia nigra, ventral tegmental area, nucleus linearis, and dorsal and medial raphe nuclei), and the diencephalic volume of interest included the thalamus and hypothalamus. A two-person inter-rater and a single intrarater reliability (intraclass correlation coefficients) of the original procedure were 0.90 and 0.99 for striatum, 0.93 and 0.97 for diencephalon, 0.81 and 0.99 for brainstem and 0.92 to 0.96 for cerebellum.

DAT binding availability was estimated by using regional count densities measured from striatal and cerebellar volumes of interest in the following equation: [striatum-cerebellum]/cerebellum $=V_{3}{ }^{\prime \prime} . V_{3}^{\prime \prime}$ is proportional to transporter number (ie, $B_{\max }$ ) under equilibrium conditions, given assumptions of invariant transporter affinity and nonspecific binding. SERT binding availability was estimated by substituting, separately, diencephalic and brainstem for striatal volume of interest regional radioactivities in this equation.

\section{Statistical Analysis}

Healthy subjects' data were evaluated using repeatedmeasures analysis of variance (RMANOVA) with withinsubject factor of time (scans 1,2, and 3) for each group. The RMANOVAs were tested for lack of sphericity, and HuynhFeldt adjustments were made to the degree of freedom to reduce type I error. As a result of multiple comparisons (2 group $* 3$ regions), $p$ values less than 0.012 were considered as a significant main effect by RMANOVA, based on Bonferroni correction. A significant main effect by RMANOVA was followed by paired $t$-test with Bonferroni correction. Correlation was analyzed with Pearson's correlation test. Depressed subjects' data were analyzed using RMANOVA for the subjects who completed three scans. Paired $t$-test was applied for all available data between scans. All analyses were done with SPSS 10.0.0.

\section{RESULTS}

\section{Healthy Subjects}

Subjects' compliance to the medications was very good, based on both self-reports (two subjects of each group 
missed 1 dose during the entire study) and plasma levels of bupropion. In Group 1, the mean plasma levels of bupropion, hydroxybupropion, and erythro/threobupropion on day 7 were $54.3 \pm 25.4 \mathrm{ng} / \mathrm{mL}$ (range 25.6-94.2), $545 \pm 351 \mathrm{ng} / \mathrm{mL}$ (range $243-1310$ ), and $283 \pm 116 \mathrm{ng} / \mathrm{mL}$ (range 141-446), respectively. On day 15, the mean plasma levels were $39.2 \pm 19.3 \mathrm{ng} / \mathrm{mL}$ (range 6.3-73.6), $558 \pm$ $321 \mathrm{ng} / \mathrm{mL}$ (range 70.3-934), and $471 \pm 281 \mathrm{ng} / \mathrm{mL}$ (range 254-894) for the parent compound and two metabolites, respectively. In Group 2, the mean plasma levels on day 15 were $34.8 \pm 23.0 \mathrm{ng} / \mathrm{mL}$ (range 3.0-72.0), $320 \pm 217 \mathrm{ng} / \mathrm{mL}$ (range 38.3-662), and $174 \pm 105 \mathrm{ng} / \mathrm{mL}$ (range 21.6-362), respectively.

After 8 days of treatment with citalopram (Group 2), radioligand binding to SERT in both brainstem and diencephalon was reduced by 51.4 and $39.4 \%$, respectively (Figure 1a). The reductions remained statistically significant to a similar degree during bupropion augmentation (day 16) (main effects of RMANOVA $p<0.001$ ). The changes on days 8 and 16 compared with day 0 were also statistically significant in paired comparisons (all $p<0.001$ ). There was no significant difference in the transporter binding between days 8 and $16(p=0.6$ for brainstem and $p=0.8$ for diencephalon). This suggested the persistent occupancy of SERT by citalopram for the interval between days 8 and 16 . On the other hand, two different doses of bupropion (Group 1) did not significantly change SERT binding for 16 days (main effects of RMANOVA $p=0.1$ and 0.7 in the brainstem and the diencephalon, respectively) (Figure 1a). Removing the two subjects who had taken loratidine prior to the study or had been on nadolol during the study did not change the results (main effects of RMANOVA $p=0.2$ and 0.5 in the brainstem and the diencephalon, respectively).

DAT binding was not significantly altered by two different doses of bupropion in Group 1 (main effect of RMANOVA $p=0.4$ ) (Figure $1 \mathrm{~b}$ ). Plasma bupropion and its metabolites (hydroxybupropion and erythro/threobupropion) did not significantly correlate with the striatal binding on days 8 and $16(p>0.18)$. Removing the two subjects who had taken loratidine prior to the study or had been on nadolol during the study did not change the results (main effects of RMANOVA $p=0.4$ ). In contrast, citalopram significantly but modestly increased the binding by $17.0 \%$ on day 8 and $15.4 \%$ on day 16 , respectively (main effect of RMANOVA $p=0.005$; significant after Bonferroni correction) (Figure $1)$. Changes on days 8 and 16 compared with day 0 were statistically significant ( $p=0.012$ and 0.006 , respectively). The difference between days 8 and 16 was not significant $(p=0.5)$.

Cerebellar activity (i.e., nondisplaceable uptake) did not significantly change during the course of the study, whether measured as absolute units of activity $(\mathrm{Bq} / \mathrm{mL})$ or as $\%$ injected dose (\%ID/L). Scan 1: $3608 \pm 867 \mathrm{~Bq} / \mathrm{mL}$ and $1.7 \pm 0.3 \% \mathrm{ID} / \mathrm{L}$; scan $2: 4013 \pm 822$ and $1.8 \pm 0.3 \% \mathrm{ID} / \mathrm{L}$; scan 3: $3973 \pm 844$ and $1.8 \pm 0.3 \%$ ID/L; $p>0.1$ for absolute concentration and $p>0.3$ for $\% \mathrm{ID} / \mathrm{L}$.

\section{Depressed Patients}

Patients HDRS was decreased to $16.3 \pm 3.8$ at the second scan and $12.5 \pm 5.4$ at the third scan. The correlation between treatment response and SERT bindings will be
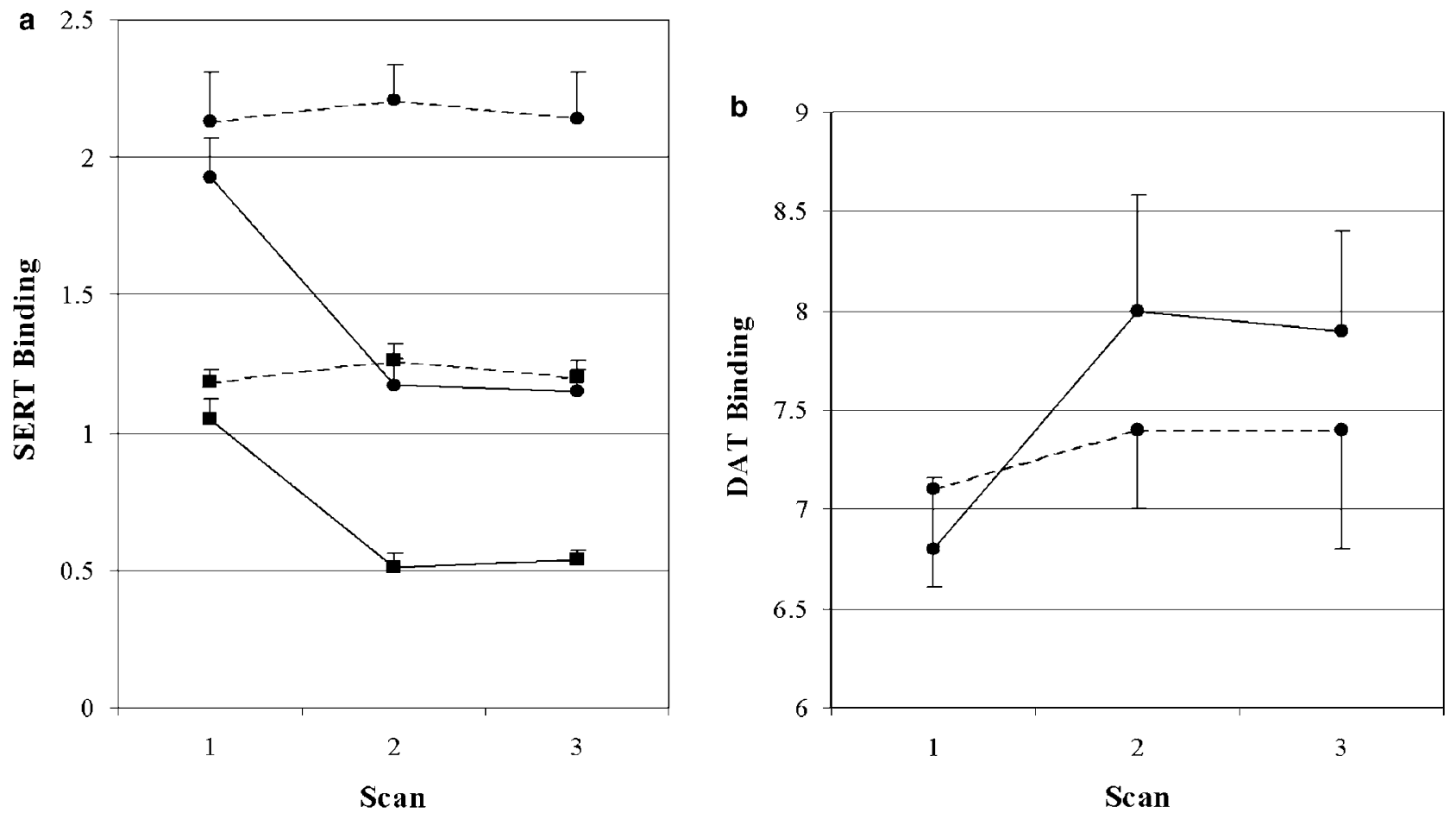

Figure I SERT (a) and DAT (b) availabilities during antidepressant administration. Group I ( $N=8$, dashed line) received bupropion SR I00 mg/day between scans I and 2 (for 8 days) and $200 \mathrm{mg} /$ day between scans 2 and 3 (for 8 days). Group 2 ( $N=9$; solid line) received citalopram $40 \mathrm{mg} /$ day between scans 1 and 2 (8 days) and both citalopram $40 \mathrm{mg} /$ day and bupropion SR $100 \mathrm{mg} /$ day between scans 2 and 3 ( 8 days). Transporter availabilities are shown for brainstem (square) and diencephalon (circle) in (a) and striatum (circle) in (b). Data are expressed as mean \pm SEM of $V_{3}^{\prime \prime}$ : [brainstem, diencephalon, or striatum activity-cerebellum activity]/cerebellum activity). 
reported elsewhere. Similar to the healthy subjects, SERT binding was decreased during SSRI (paroxetine) treatment. The changes were $36.5 \%$ from the first $\left(V_{3}{ }^{\prime \prime}=1.78 \pm 0.54\right)$ to the second scan $\left(V_{3}^{\prime \prime}=1.13 \pm 0.38 ; p<0.001\right)$ and $32.6 \%$ from the first to the third scan $\left(V_{3}^{\prime \prime}=1.20 \pm 0.40 ; p<0.001\right)$ in the brainstem ( $p=0.8$ between the second and the third scan), and $29.1 \%$ from the first $\left(V_{3}^{\prime \prime}=2.99 \pm 0.97\right)$ to the second scan $\left(V_{3}^{\prime \prime}=2.12 \pm 0.64 ; p=0.006\right)$ and $23.4 \%$ from the first to the third scan $\left(V_{3}^{\prime \prime}=2.29 \pm 0.62\right.$; $p=0.002)$ in the diencephalon $(p=0.8$ between the second and the third scan). The changes in both regions were statistically significant on analysis with RMANOVA (main effect $p<0.001$ and $p=0.002$, respectively). DAT binding in striatum increased by $5.6 \%$ between the first $\left(V_{3}^{\prime \prime}=8.93 \pm 2.79\right)$ and the second scan $\left(V_{3}^{\prime \prime}=9.43 \pm 2.48\right)$ and by $16.5 \%$ between the first and the third scan $\left(V_{3}^{\prime \prime}=10.4 \pm 1.9\right)(p=0.55$ for the first $v s$ the second scan and $p=0.25$ for the first $v s$ the third scan). Although similar to trends in healthy subjects' data, these changes were not statistically significant with RMANOVA $(p=0.35)$.

Cerebellar activity in depressed patients did not significantly change during the course of the study, whether measured as absolute units of activity $(\mathrm{Bq} / \mathrm{mL})$ or as (\%ID/ L). Scan 1: $2437 \pm 2123 \mathrm{~Bq} / \mathrm{mL}$ and $1.6 \pm 1.4 \% \mathrm{ID} / \mathrm{L}$; scan 2 : $2731 \pm 1073$ and $1.8 \pm 0.7 \%$ ID/L; scan 3: $2631 \pm 763$ and $1.8 \pm 0.5 \% \mathrm{ID} / \mathrm{L} ; p>0.5$ for both values.

\section{DISCUSSION}

The major goal of the present study was to measure changes in human SERT and DAT availabilities during the administration of antidepressants. Citalopram caused an expected reduction in radioligand binding to SERT. However, citalopram paradoxically increased DAT availability with 8 days administration, an effect that was maintained with chronic administration for a total of 16 days. We observed similar trends in the course of paroxetine treatment in depressed patients. In contrast, bupropion, neither by itself nor as an augmentation to citalopram, showed a significant effect on radioligand binding to either DAT or SERT.

Reductions of $\left[{ }^{123} \mathrm{I}\right] \beta$-CIT binding by citalopram and paroxetine were consistent with their profile as SSRIs (Hyttel, 1977, 1982) and considered to be the result of transporter occupancy. Pirker et al (1995) reported that SERT binding measured with $\left[{ }^{123} \mathrm{I}\right] \beta$-CIT was $46 \%$ lower in hypothalamus/midbrain region of depressed patients taking citalopram (20-60 mg/day) compared with age- and gendermatched controls (healthy subjects and patients with neurological diseases). Similarly, Tauscher et al (1999) reported a $40 \%$ occupancy of midbrain $\left[{ }^{123} \mathrm{I}\right] \beta$-CIT activity in a single patient with depression and bulimia nervosa taking fluoxetine $60 \mathrm{mg} /$ day. Hiltunen et al (1998) found $52 \%$ reduction in midbrain $\left[{ }^{123} \mathrm{I}\right]$ nor- $\beta$-CIT binding by $30 \mathrm{mg}$ citalopram. Mice treated with physiological doses of SSRIs (paroxetine or fluoxetine; the potency of citalopram to inhibit 5-HT uptake is intermediate between these drugs) was measured $\left[{ }^{125} \mathrm{I}\right] \beta$-CIT binding in the hypothalamus and found to induce $40-80 \%$ decrease in the binding (Scheffel et $a l, 1994)$. The results in the current study largely replicate these previous studies, with therapeutic doses of citalopram inducing $40-50 \%$ occupancy of midbrain/diencephalon $\left[{ }^{123} \mathrm{I}\right] \beta$-CIT activity. The fact that the reduction of midbrain $\left[{ }^{123} \mathrm{I}\right] \beta$-CIT activity was the same for all three doses of citalopram (20, 40, and $60 \mathrm{mg}$ ) suggests virtually $100 \%$ occupancy of SERT (Tauscher et al, 1999). Thus, the residual activity could represent unusually high nonspecific binding in this region or, more likely, residual binding to DAT. This interpretation is consistent with recent PET studies of SERT using the selective SERT tracers $\left[{ }^{11} \mathrm{C}\right] \mathrm{McN} 5652$ or $\left[{ }^{11} \mathrm{C}\right] \mathrm{DASB}$. Parsey et al (2000) reported that $60-80 \mathrm{mg}$ of paroxetine occupied virtually $100 \%$ of SERT in thalamic, midbrain, and striatal regions measured with $\left[{ }^{11} \mathrm{C}\right] \mathrm{McN} 5652$. Meyer et al (2001) showed approximately $80 \%$ occupancy of striatal SERT by $20 \mathrm{mg}$ of paroxetine measured with $\left[{ }^{11} \mathrm{C}\right] \mathrm{DASB}$ in depressed patients.

Interestingly, we found that the availability of SERT remained the same between days 8 and 16 of continuous citalopram treatment and for 6 weeks of paroxetine in depressed patients. This result suggests that the transporter density was unaltered in this limited but chronic period. Consistent with our results, several rodent studies found no change in SERT density after 14-21 days of citalopram treatment (Hyttel et al, 1984; Graham et al, 1987; Kovachich et al, 1992; Cheetham et al, 1993; Spurlock et al, 1994). By contrast, a recent careful study (Benmansour et al, 1999) showed $80-90 \%$ downregulation of rat hippocampal SERT density after chronic SSRI treatment of paroxetine or sertraline for 21 days.

A novel finding in the present study is the increase in DAT binding associated with citalopram administration, similarly observed during paroxetine treatment in depressed patients. This result is unlikely to be an artifact of the ratio method used as the outcome measure in this study - that is $V_{3}{ }^{\prime \prime}$, the ratio of specific to nondisplaceable activity. That is, the nondisplaceable activity in cerebellum was not significantly changed during the course of drug administration, and the changes in striatal $V_{3}^{\prime \prime}$ would therefore reflect DAT binding. In addition, this result is unlikely to be caused by occupancy of the transporter by endogenous dopamine. Previous imaging studies in monkeys showed no effect of marked increases in extracellular dopamine levels on $\left[{ }^{123} \mathrm{I}\right] \beta$-CIT striatal uptake (Laruelle et al, 1993). Furthermore, three previous studies might suggest the present finding of SSRI-induced increase in striatal DAT binding. In one, mice treated with a high dose of fluoxetine (10 mg/kg, i.p.) showed $10-30 \%$ higher striatal $\left[{ }^{125} \mathrm{I}\right] \beta-\mathrm{CIT}$ binding (Scheffel et al, 1994). In the second, administration of a tricyclic antidepressant, clomipramine, caused increase in rat striatal $\left[{ }^{125} \mathrm{I}\right] \beta$-CIT binding (Fujita et al, 1997). The increase was correlated with the blockade of midbrain SERT binding by the drug, suggesting an underlying interaction between serotonin and dopamine systems. Finally, increased DAT mRNA was reported in the ventral tegmental area/substantia nigra of rats treated with desipramine (Petrie et al, 1998). Hiltunen et al (1998) and Tauscher et al (1999) described higher striatal binding in a single human subject on SSRIs (fluoxetine and citalopram, respectively) in their preliminary reports. By contrast, Pirker et al (1995) did not find significant change in striatal binding induced by citalopram treatment. The different finding from the present study could well be because of their use of a between-subject design rather than the more sensitive within-subject design in the current study. In 
addition, the comparison group used by Pirker et al (1995) included patients with neurological disorders.

The underlying mechanism of increased DAT binding by SSRIs is unknown. Modulation of dopamine system by SSRIs has been reported, including reduced dopamine extracellular levels in striatum measured with microdialysis (Ichikawa and Meltzer, 1995; Smith et al, 2000). One widely proposed explanation for the reduction was that serotonin receptors located on dopamine terminals or on interneurons that normally facilitate dopamine release were desensitized by SSRI administration (Parsons and Justice, 1993). The current results suggest another explanation for low extracellular dopamine induced by SSRIs: increased DAT levels could more efficiently remove dopamine from the synapse. Since $V_{3}^{\prime \prime}$ binding potential is proportional to $B_{\max } / K_{\mathrm{d}}$ under equilibrium conditions, an increase in transporter affinity $\left(1 / K_{\mathrm{d}}\right)$ to the radioligand can be another reason for the increase in DAT binding. The significance and mechanism of elevated DAT binding during SSRI treatment will need to be further examined.

Another unexpected finding of this study was that two different clinical doses of bupropion did not inhibit striatal DAT binding, a result generally inconsistent with its pharmacological profile (Cunning et al, 1979; Stathis et al, 1995). The plasma levels of bupropion and subjects' selfreport appeared to exclude the possibility that the result was because of low compliance. Some investigators question the DAT selectivity of bupropion and suggest it may be more active on noradrenergic transmission (Ascher et al, 1995; Terry and Katz, 1997). Doses of bupropion that were behaviorally active in antidepressant tests appeared to produced their effects via noradrenergic rather than dopaminergic inhibition (Cooper et al, 1994), consistent with other human studies that failed to demonstrate a dopamine-mediated neurohormonal effect with clinical doses of bupropion (Laakmann et al, 1982; Whiteman et $a l, 1982)$. The negligible effect of bupropion on striatal DAT binding in the present study is in accordance with these previous studies and suggest that antidepressant action of bupropion is attributed to mechanisms other than inhibition of DAT.

SSRIs cause sexual dysfunction more frequently than bupropion (Modell et al, 1997; Segraves et al, 2000; Coleman et al, 2001). The current results show a differential effect of citalopram and bupropion on striatal DAT levels. Within limitations discussed above, the SSRI-induced elevation in DAT could be functionally linked to an overall decrease in dopaminergic neurotransmission with more efficient removal of the transmitter from the synaptic region. Decreased dopamine transmission may be involved in sexual arousal (Segraves, 1989), and numerous uncontrolled studies have supported the use of dopamine agonists for treatment of SSRI-induced ejaculatory dysfunction (Rosen et al, 1999). Bupropion has a lower risk of sexual dysfunction than SSRIs (Modell et al, 1997; Segraves et al 2000; Coleman et al 2001). The difference in the prevalence of sexual dysfunction between SSRIs and bupropion may be because of their differential effect on DAT activities.

A few other limitations should be mentioned. Plasma SSRI levels (citalopram and paroxetine) were not obtained and limited us to assess subjects' compliance to the drugs and to correlate the actual drug effect with SERT bindings.
The lack of test-retest reproducibility study of the SERT binding is another limitation.

In summary, the present in vivo human study examined the effects of SSRIs and bupropion on both the occupancy and adaptive changes in DAT and SERT availability. Consistent with previous reports, therapeutic doses of citalopram induced about $50 \%$ reduction in brainstem and diencephalic activity of $\left[{ }^{123} \mathrm{I}\right] \beta$-CIT, suggesting that the residual $50 \%$ activity reflects DAT in these regions. Two unexpected findings were that bupropion induced negligible DAT occupancy and that citalopram administration increased striatal DAT levels. Similar results during paroxetine treatment of depressed patients support the findings with citalopram in healthy subjects, although a larger study in patients is clearly indicated. The present study demonstrates the utility of neuroreceptor imaging to examine mechanisms of both the efficacy and side effect of psychotropic agents.

\section{ACKNOWLEDGEMENTS}

The authors gratefully acknowledge the technical support of M Early and A Perez for imaging, S Giddings for subject recruitment, and L Amici and N Sheung for radiochemistry. This work was supported in part by funds from Pfizer Inc., NARSAD Independent Investigator Award (RT Malison), and Japan Foundation for Aging and Health (PI, S Yamawaki, Hiroshima University).

\section{REFERENCES}

Ascher J, Cole J, Colin JN, Feighner J, Ferris R, Fibiger H et al (1995). Bupropion: a review of its mechanism of antidepressant activity. J Clin Psychiatry 56: 395-401.

Ashton A, Rosen R (1998). Bupropion as an antidote for serotonin reuptake inhibitor-induced sexual dysfunction. J Clin Psychiatry 59: 112-115.

Backstrom I, Bergstrom M, Marcusson J (1989). High affinity $\left[{ }^{3} \mathrm{H}\right]$ paroxetine binding to serotonin uptake sites in human brain tissue. Brain Res 486: 261.

Baldwin RM, Zea-Ponce Y, Zoghbi SS, Laruelle M, Al-Tikriti MS, Sybirska EH et al (1993). Evaluation of the monoamine uptake site ligand $\left[{ }^{123} \mathrm{I}\right]$ methyl $3 \beta$-(4-iodophenyl)tropane- $2 \beta$-carboxylate $\left(\left[{ }^{123} \mathrm{I}\right] \beta-\mathrm{CIT}\right)$ in nonhuman primates: pharmacokinetics, biodistribution, and SPECT brain imaging coregistered with MRI. Nucl Med Biol 20: 597-606.

Benfield P, Heel R, Lewis S (1986). Fluoxetine: a review of its pharmacodynamic and pharmacokinetic properties, and therapeutic efficacy in depressive illness. Drugs 32: 481-508.

Benmansour S, Cecchi M, Morilak D, Gerhardt G, Javors M, Gould $\mathrm{G}$ et al (1999). Effects of chronic antidepressant treatments on serotonin transporter function, density, and mRNA level. $J$ Neurosci 19: 10494-10501.

Cheetham S, Viggers J, Slater N, Heal D, Buckett W (1993). $\left[{ }^{3} \mathrm{H}\right]$ Paroxetine binding in rat frontal cortex strongly correlates with $\left[{ }^{3} \mathrm{H}\right] 5-\mathrm{HT}$ uptake: effect of administration of various antidepressant treatments. Neuropharmacology 32: 737-743.

Clayton A, McGarvey E, Abouesh A, Pinkerton R (2001). Substitution of an SSRI with bupropion sustained release following SSRI-induced sexual dysfunction. J Clin Psychiatry 62: $185-190$.

Coleman C, King B, Bolden-Watson C, Book M, Segraves R, Richard N et al (2001). A placebo-controlled comparison of the 
effects on sexual functioning of bupropion sustained release and fluoxetine. Clin Ther 23: 1040-1058.

Cooper B, Wang C, Cox R, Norton R, Shea V, Ferris R (1994). Evidence that the acute behavioral and electrophysiological effects of bupropion (Wellbutrin) are medicated by a noradrenergic mechanism. Neuropsychopharmacology 11: 133-141.

Cortes R, Soranoi E, Pazos A, Probst A, Palacios JM (1988). Autoradiography of antidepressant binding sites in the human brain: localization using $\left[{ }^{3} \mathrm{H}\right]$ imipramine and $\left[{ }^{3} \mathrm{H}\right]$ paroxetine. Neuroscience 27: 473-496.

Cunning H, Goff D, Leach M, Miller A, Tateson J, Wheatley P (1979). The involvement of dopamine in the central actions of bupropion, a new antidepressant. Br J Pharmacol 66: 104P.

D'Amato RJ, Largent BL, Snowman AM, Snyder SH (1987). Selective labeling of serotonin uptake sites in rat brain by $\left[{ }^{3} \mathrm{H}\right]$ citalopram contrasted to labeling of multiple sites by [ ${ }^{3} \mathrm{H}$ ]imipramine. J Pharmacol Exp Ther 242: 364-371.

De Keyser J, De Backer J-P, Ebinger G, Vauquelin G (1989). $\left[{ }^{3} \mathrm{H}\right]$ GBR 12935 binding to dopamine uptake sites in the human brain. J Neurochem 53: 1400-1404.

Fujita $M$, Takatoku $K$, Nishiura $M$, Kobayashi $K$, Inoue $O$, Nishimura $\mathrm{T}$ (1997). Enhancement of $\left[{ }^{123} \mathrm{I}\right] \beta-\mathrm{CIT}$ binding in the striatum with clomipramine: is there a serotonin-dopamine interaction? Eur J Nucl Med 24: 403-408.

Graham D, Tahraoui L, Langer SZ (1987). Effect of chronic traetment with selective monoamine oxidase inhibitors and specific 5-hydroxytryptamine uptake inhibitors on $\left[{ }^{3} \mathrm{H}\right]$ paroxetine binding to cerebral cortical membranes of the rat. Neuropharmacology 26: 1087-1092.

Hiltunen J, Akerman KK, Kuikka JT, Bergstrom KA, Halldin C, Nikula $\mathrm{T}$ et al (1998). Iodine-123 labeled nor- $\beta$-CIT as a potential tracer for serotonin transporter imaging in the human brain with single-photon emission tomography. Eur J Nucl Med 25: $19-23$.

Hyttel J (1977). Neurochemical characterization of a new potent and selective serotonin uptake inhibitor: Lu 10-171. Psychopharmacology 51: 225-233.

Hyttel J (1982). Citalopram: pharmacological profile of a specific serotonin uptake inhibitor with antidepressant activity. Prog Neuropsychopharmacol Biol Psychiatry 6: 277.

Hyttel J, Overo K, Arnt J (1984). Biochemical effects and drug levels in rats after long-term treatment with the specific 5-HTuptake inhibitor, citalopram. Psychopharmacology 83: 20-27.

Ichikawa J, Meltzer H (1995). Effect of antidepressants on striatal and accumbens extracellular dopamine levels. Eur J Pharmacol 281: 255-261.

Jacobsen L, Staley JK, Malison R, Zoghbi S, Seibyl JP, Kosten T, Innis R (2000). Elevated central serotonin transporter binding availability in acutely abstinent cocaine-dependent patients. $\mathrm{Am}$ J Psychiatry 157: 1134-1140.

Kovachich G, Aronson C, Brunswick D (1992). Effect of repeated administration of antidepressants on serotonin uptake sites in limbic and neocortical structures of rat brain determined by quantitative autoradiography. Neuropsychopharmacology 7: 317324.

Laakmann G, Hoffmann N, Hofschuster E (1982). The lack of effect of bupropion $\mathrm{HCl}$ (Wellbutrin) on the secretion of growth hormone and prolactin in humans. Life Sci 30: $1725-1732$.

Laruelle M, Vanisberg MA, Maloteaux JM (1988). Regional and subcellular localization in human brain of $\left[{ }^{3} \mathrm{H}\right]$ paroxetine binding, a marker of serotonin uptake sites. Biol Psychiatry 24: 299-309.

Laruelle M, Baldwin RM, Malison RT, Zea-Ponce Y, Zoghbi SS, AlTikriti MS et al (1993). SPECT imaging of dopamine and serotonin transporters with $\left[{ }^{123} \mathrm{I}\right] \beta$-CIT: pharmacological characterization of brain uptake in nonhuman primates. Synapse 13: 295-309.
Laruelle M, Wallace E, Seibyl JP, Baldwin RM, Zea-Ponce Y, Zoghbi SS et al (1994). Graphical, kinetic, and equilibrium analyses of in vivo $\left[{ }^{123} \mathrm{I}\right] \beta$-CIT binding to dopamine transporters in healthy human subjects. J Cereb Blood Flow Metab 14: 982-994.

Malison RT, Price LH, Berman R, Pelton GH, Carpenter L, Sanacora G et al (1998). Reduced brain serotonin transporter availability in major depression as measured by $\left[{ }^{123} \mathrm{I}\right] \beta$-CIT. Biol Psychiatry 44: 1090-1098.

Meyer J, Wilson A, Ginovart N, Goulding V, Hussey D, Hood K et al (2001). Occupancy of serotonin transporters by paroxetine and citalopram during treatment of depression: a $\left[{ }^{11} \mathrm{C}\right] \mathrm{DASB}$ PET imaging study. Am J Psychiatry 158: 1843-1849.

Modell J, Katholi C, DePalma R (1997). Comparative sexual effects of bupropion, fluoxetine, paroxetine, and sertraline. Clin Pharmacol Ther 61: 476-487.

Neumeyer JL, Wang S, Milius RA, Baldwin RM, Zea-Ponce Y, Hoffer PB et al (1991). [ $\left.{ }^{123} \mathrm{I}\right]-2-\beta$-Carbomethoxy-3- $\beta$-(4-iodophenyl)-tropane ( $\beta$-CIT). High affinity SPECT radiotracer of monoamine reuptake sites in brain. J Med Chem 34: 3144-3146.

Parsey R, Kegeles L, Hwang D, Simpson N, Abi-Dargham A, Mawlawi $\mathrm{O}$ et al (2000). In vivo quantification of brain serotonin transporters in humans using $\left[{ }^{11} \mathrm{C}\right] \mathrm{McN}$ 5652. J Nucl Med 41: 1465-1477.

Parsons L, Justice JJ (1993). Serotonin and dopamine sensitization in the nucleus accumbens, ventral tegmental area, and dorsal raphe nucleus following repeated cocaine administration. $J$ Neurochem 61: 1611-1619.

Pelizzari CA, Chen GTY, Spelbring DR, Weichselbaum RR, Chen CT (1989). Accurate three dimensional registration of CT, PET, and/or MR images of the brain. J Comput Assist Tomogr 13: 20-26.

Petrie E, Veith R, Szot P (1998). Bupropion and desipramine increase dopamine transporter mRNA expression in the ventral tegmental area/substantia nigra of rat brain. Prog Neuropsychopharmacol Biol Psychiatry 22: 845-856.

Pirker W, Asenbaum S, Kasper S, Walter H, Angelberger P, Koch G et al (1995). $\beta$-CIT SPECT demonstrates blockade of 5HT-uptake sites by citalopram in the human brain in vivo. J Neural Transm 100: $247-256$.

Rajeevan N, Zubal IG, Ramsby SQ, Zoghbi SS, Seibyl J, Innis RB (1998). Significance of nonuniform attenuation correction in quantitative brain SPECT imaging. J Nucl Med 39: 1719-1726.

Rosen R, Lane R, Menza M (1999). Effects of SSRIs on sexual function: a critical review. J Clin Psychopharmacol 19: 67-85.

Sanchez C, Hyttel J (1999). Comparison of the effects of antidepressants and their metabolites on reuptake of biogenic amines and on receptor binding. Cell Mol Neurobiol 19: 467-489.

Schatzberg A (2000). New indications for antidepressants. J Clin Psychiatry 61: 9-17.

Scheffel U, Kim S, Cline E, Kuhar M (1994). Occupancy of the serotonin transporter by fluoxetine, paroxetine, and sertraline: in vivo studies with [ $\left.{ }^{125} \mathrm{I}\right] \mathrm{RTI}-55$. Synapse 16: 263-268.

Segraves R (1989). Effects of psychotropic drugs on human erection and ejaculation. Arch Gen Psychiatry 46: 275-284.

Segraves R, Kavoussi R, Hughes A, Batey S, Johnston J, Donahue R et al (2000). Evaluation of sexual functioning in depressed outpatients: a double-blind comparison of sustained-release bupropion and sertraline treatment. J Clin Psychopharmacol 20: 122-128.

Seibyl JP, Laruelle M, van Dyck CH, Wallace E, Baldwin RM, Zoghbi $S$ et al (1996). Reproducibility of $\left[{ }^{123} \mathrm{I}\right] \beta$-CIT SPECT brain measurement of dopamine transporters in healthy human subjects. J Nucl Med 37: 222-227.

Smith T, Kuczenski R, George-Friedman K, Malley J, Foote S (2000). In vivo microdialysis assessment of extracellular serotonin and dopamine levels in awake monkeys during sustained fluoxetine administration. Synapse 38: 460-470. 
Spitzer R, Williams J, Gibbon M, First M (1990a). Structured Clinical Interview for DSM-III-R-Non-Patient Edition (SCID-NP, Ver. 1.0). American Psychiatric Press: Washington, DC.

Spitzer R, Williams J, Gibbon M, First M (1990b). Structured Clinical Interview for DSM-III-R-Patient Edition (SCID-P, Ver. 1.0). American Psychiatric Press: Washington, DC.

Spurlock G, Buckland P, O’Donovan M, McGuffin P (1994). Lack of effect of antidepressant drugs on the levels of mRNAs encoding serotonergic receptors, synthetic enzymes and 5-HT transporters. Neuropharmacology 33: 433-440.

Staley J, Krishnan-Sarin S, Zoghbi S, Tamagnan G, Fujita M, Seibyl $J$ et al (2001). Gender differences in dopamine and serotonin transporter availability in nonsmokers and tobacco smokers. Synapse 41: 275-284.

Stathis M, Scheffel U, Lever S, Boja J, Carroll F, Kuhar M (1995). Rate of binding of various inhibitors at the dopamine transporter in vivo. Psychopharmacol 119: 376-384.
Tauscher J, Pirker W, deZwaan M, Asenbaum S, Brucke T, Kasper S (1999). In vivo visualization of serotonin transporters in the human brain during fluoxetine treatment. Eur Neuropsychopharmacol 9: 177-179.

Terry P, Katz J (1997). Dopaminergic mediation of the descriptive stimulus effects of bupropion in rates. Psychopharmacology 134: 201-212.

Whiteman P, Peck A, Fowle A, Smith P (1982). Bupropion fails to affect plasma prolactin and growth-hormone in normal subjects. Br J Clin Pharmacol 13: 743-745.

Willetts J, Lippa A, Bernard B (1999). Clinical development of citalopram. J Clin Psychopharmacol 19: S36-S46.

Wong D, Bymaster F, Engleman E (1995). Prozac (fluoxetine, Lilly 110140), the first selective serotonin uptake inhibitor and an antidepressant drug: twenty years since its first publication. Life Sci 57: 411-441. 